Science, Technology and Development 34 (3): 147-154, 2015

ISSN 0254-6418 / DOI: 10.3923/std.2015.147.154

(C) 2015 Pakistan Council for Science and Technology

\title{
Estimating Spatial Population Structure through Quantification of Oil Content and Phenotypic Diversity in Pakistani Castor Bean (Ricinus communis L.) Germplasm
}

\author{
Muhammad Arif, Haris Khurshid, Sadar Uddin Siddiqui, Shakeel Ahmad Jatoi, \\ Sohail Ahmad Jan, M. Ilyas, Shahid Ali Khan, Ahson Khan, \\ Muhammad Ishaq Ibrahim, Noor Saleem and Abdul Ghafoor \\ Plant Genetic Resources Institute, National Agricultural Research Center, Islamabad, Pakistan
}

\begin{abstract}
Castor bean (Ricinus communis L.) is an important non-edible oilseed crop containing 45-58\% oil mainly used in pharmaceutical, petroleum, biofuels, chemicals and textile industry. We evaluated 63 castor beans accessions from Pakistani origin to determine population structure and extent of genetic divergence in local germplasm viz-a '-viz 14 agronomic traits and oil content. Higher phenotypic variability was reported for number of branches plant ${ }^{-1}$, plant height, days to germination and days to flowering. Maximum oil content $58 \%$ was found in genotype 21102 followed by 57\% in 21447, 5624828 and 54\% in 24835 and 21455 . The dissimilarity coefficient matrix revealed accession pairs 24816 and 24821, 24821 and 24829, 21559 and 24821 as most diverse with highest Euclidean distances i.e. 11.45, 10.49 and 9.88, respectively. Subsequent cluster analysis distributed all genotypes into six major groups on the basis of morphological characterization. In PCA analysis, 5 of the 14 PCs had Eigen value $>1$, which explained $66.24 \%$ of the total variation, partitioning population into four sub-populations akin to their distinctive agro-morphological attributes. These sub-populations originated from common habitat of adjacent districts i.e., Bahawalpur, Lodhran, Multan, Muzaffargarh and D.G Khan with matching ecogeographic factors signifying availability of genetic diversity in south Punjab. We suggest utilization of Pakistani castor bean germplasm diversity, while breeding for yield components like capsule size, number and size of seed and oil content. In addition, further studies are recommended, focusing on biochemical and molecular basis of variation to fully explore local genetic diversity in the crop.
\end{abstract}

Key words: Genetic divergence, castor beans, population, geographical distribution

\section{INTRODUCTION}

Castor bean (Ricinus communis L.) is one of the important non-edible oilseed crops belonging to family Euphorbiaceae, which comprises of about 6,300 species that also include cassava (Manihot esculenta), rubber tree (Hevea brasiliensis) and physic nut (Jatropha curcas). Castor bean has $(2 n=20)$ has been originated in Ethiopia and regarded as indigenous to Eastern Africa. It is cultivated as perennial shrub plant in tropical region, where its height range from $10-13 \mathrm{~m}$, while in temperate region it is grown as annual crop and its height varies from 1.5-2.4 m (Anjani, 2012; Falasca et al., 2012). Once established, castor bean can quickly spread and is considered as an invasive weed in many countries.

Castor bean is primarily of economic interest as a source of seed oil that is used in the production of high-quality lubricants, hydraulic fluids, paints, dyes, coatings, inks, cold resistant plastics, waxes, polishes, nylon etc. The seeds are full of oil and its composition varies from $46-55 \%$ by weight. The castor oil products are more useful than petrochemicals due to their low toxicity, give more energy, environment friendly and are easily biodegradable (Ogunniyi, 2006).

Breeders have given great attention to this crop for development of new varieties (Sujatha et al., 2008). Success in this crop is based on looking for genetic variations for increased seed yield, early maturity, high oil content and resistance to various biotic and abiotic stresses (Weiss, 2000; Hegde et al., 2003). It is necessary to characterize the genetic diversity present across $R$. communis germplasm from different geographic regions to develop a genotyping scheme that links castor bean evidence to a particular source, geographic region or batch.

Agro-morphological diversity is the first step to characterize different qualitative and quantitative traits of interest among genotypes and assess genetic structure of broad genetic population at species and sub-species level

Corresponding Author: Haris Khurshid, Evaluation Lab, Plant Genetic Resources Institute, National Agricultural Research Center, Park Road, Islamabad, Pakistan Tel: +92-51-8443715, +92-345-6119217 
(Smith et al., 1991). Phenotypic divergence is important to study several agronomic and physiological characters at a time (Peeters and Martinelli, 1989). For this purpose various analysis methods are available such as cluster analysis and Principal Component Analysis (PCA) that can be used to identify the diverse ranges of genotypes into groups for trait of interest and to study phylogenetic relationship among different types of species and sub species (Camussi et al., 1985; Nooryazdan et al., 2010). In the present study, we investigated genetic divergence and structure of Pakistani castor bean population using agro-morphological characters and oil content in relation to its broad agro-ecological distribution across the country.

\section{MATERIALS AND METHODS}

The experiment was conducted at Plant Genetic Resources Institute (PGRI), National Agricultural Centre, Islamabad Pakistan. Sixty three castor beans lines of Pakistani origin including eight varieties from Bahawalpur were grown during summer, 2010 using augmented field design (Table 1). Five seeds of each genotype were sown in a single line keeping both inter and intra line spacing of

\begin{tabular}{llll}
\hline Accession & Origin & Accession & Origin \\
\hline 24815 & Lahore & 20715 & D.I Khan \\
24816 & Lahore & 22230 & Okara \\
24817 & Okara & 22184 & Ghotki \\
24818 & Sahiwal & BRC-13 & Bahawalpur \\
24819 & Khanewal & 21113 & Unknown \\
24820 & Khanewal & 21112 & Unknown \\
22237 & Multan & 21110 & Unknown \\
24821 & Khanewal & 21102 & Unknown \\
24822 & Multan & 21314 & Jhang \\
24823 & Multan & 21279 & Jhang \\
24824 & Multan & 21114 & Unknown \\
24825 & Multan & 21097 & Unknown \\
24826 & Multan & 21100 & Unknown \\
24827 & Multan & 22231 & Pakpatan \\
24828 & Muzaffargarh & BRC-18 & Bahawalpur \\
24829 & Muzaffargarh & 21343 & Layyah \\
24830 & Muzaffargarh & 21864 & Quetta \\
24832 & Lodran & 21834 & Quetta \\
24833 & Bahawalpur & 21903 & Sargodha \\
24834 & Lodran & 22150 & Loralai \\
24835 & Bahawalpur & BRC-17 & Bahawalpur \\
24836 & Khanewal & BRC-26 & Bahawalpur \\
24837 & Multan & 21106 & Unknown \\
24838 & Muzaffargarh & BRC-29 & Bahawalpur \\
21698 & Pakpatan & 21103 & Unknown \\
21685 & Bahawalpur & 21101 & Unknown \\
21559 & D.G Khan & BRC-20 & Bahawalpur \\
21484 & D.G Khan & BRC-21 & Bahawalpur \\
21455 & Attock & BRC-22 & Bahawalpur \\
24831 & Lodran & 21441 & Attock \\
21447 & Attock & 21523 & D.G Khan \\
21016 & Narowal & & \\
\hline & & &
\end{tabular}

$2 \mathrm{~m}$. Three randomly plants were selected from each line to record data for nine quantitative traits i.e., Days to Germination (DtG), Days to Flowering (DF), Plant Height (PH), number of branches plant ${ }^{-1}(\mathrm{NB})$, Capsule Length (CL mm), Capsule Width (CW mm), Seed Length (SL $\mathrm{mm}$ ) and Seed Width (SW $\mathrm{mm}$ ) and five qualitative traits i.e., Capsule Colour (CC), Leaf Colour (LC), spininess, Testa Colour (TC) and Seed Shape (SS). Also, oil content was quantified by Soxhlet apparatus extraction using hexane as extraction solvent (boiling point $68^{\circ} \mathrm{C}$ ). Seeds were dried at $103 \pm 2^{\circ} \mathrm{C}$ until water content was reduced to $10 \%(\mathrm{w} / \mathrm{w})$. Three extraction cycles $(4+2+2 \mathrm{~h})$ were carried out to completely recover oil from seeds. Seeds were carefully grounded after each extraction cycle and percentage of the collected oil in the seeds was determined gravimetrically and expressed as a weight\% relative to initial weight of the raw castor bean seeds.

Data analysis: Descriptive statistics i.e., means, variance standard deviation etc. were determined for all recorded data using M.S Excel 2010. Standardized mean values of all characters were used to compute Pearson's correlation matrix and principal component analysis using Statistica 7.0 (Stat Soft Inc. USA), while intra population Euclidean distances were calculated between all the genotypes for cluster analysis through NTSys PC 2.1 software package.

\section{RESULTS}

Descriptive statistics i.e., mean, range, variance, standard deviation and coefficient of variation results for nine quantitative traits are presented in Table 2. Higher coefficients of variation was observed for number of branches plant $^{-1}$, plant height, days to germination, days to flowering and oil content, while moderate variation was recorded for seed length and capsule width. Accessions 24828 and 21559 germinated within a week, while maximum days to germination thirteen were observed for five accessions. Accessions $21343(152.3 \mathrm{~cm})$, BRC-21 $(149.3 \mathrm{~cm}), 21455(146.3 \mathrm{~cm})$ and BRC-20 $(143.3 \mathrm{~cm})$ were tallest genotypes. Highest number of branches were recorded for 21698 (13) followed by 28828 and 21447

Table 2: Descriptive statistics of quantitative traits and \% oil content in 63 castorbean accessions and varieties

\begin{tabular}{lrrrrrr}
\hline Statistical & & & & & & \\
parameters & Mean & SD & Variance & Minimum & Maximum & CV (\%) \\
\hline DtG & 10.00 & 1.58 & 2.50 & 7.00 & 13.00 & 15.10 \\
DF & 60.52 & 8.13 & 66.07 & 39.00 & 73.00 & 13.43 \\
PH & 117.05 & 18.37 & 337.64 & 71.30 & 152.30 & 15.70 \\
NB & 7.62 & 2.17 & 4.71 & 4.00 & 13.00 & 28.50 \\
CL & 17.68 & 0.77 & 0.60 & 15.64 & 18.62 & 4.38 \\
CW & 14.83 & 1.20 & 1.44 & 10.04 & 18.17 & 8.08 \\
Seed length & 12.40 & 1.17 & 1.36 & 9.90 & 14.27 & 9.40 \\
Seed width & 7.80 & 0.54 & 0.29 & 6.52 & 9.04 & 6.93 \\
OC (\%) & 48.65 & 6.74 & 45.39 & 37.00 & 63.00 & 13.85 \\
\hline
\end{tabular}


Sci. Technol. Dev., 34 (3): 147-154, 2015

Table 3: Frequency distribution of 5 qualitative traits of 63 genotypes

\begin{tabular}{|c|c|c|c|c|c|c|c|c|c|}
\hline \multicolumn{2}{|l|}{ Capsule } & \multicolumn{2}{|l|}{ Leaf } & \multicolumn{2}{|l|}{ Spininess } & \multicolumn{2}{|l|}{ Seed } & \multicolumn{2}{|l|}{ Seed } \\
\hline Phenotype & No. & Phenotype & No. & Phenotype & No. & Phenotype & No. & Phenotype & No. \\
\hline Brown & 22 & Green & 40 & Spiny & 53 & Grey & 42 & Oblong & 45 \\
\hline Dark brown & 5 & Dark green & 9 & Spineless & 10 & Red & 10 & Ovate & 18 \\
\hline Skin & 23 & Light green & 12 & Brown & 11 & Grey & 10 & Purple & 2 \\
\hline Green & 1 & & & & & & & & \\
\hline Reddish & 2 & & & & & & & & \\
\hline
\end{tabular}

Table 4: Pearson's correlation matrix for eight morphological traits and oil content

\begin{tabular}{|c|c|c|c|c|c|c|c|c|c|}
\hline Correlation parameters & DtG & DF & $\mathrm{PH}$ & NB & CL & CW & SL & SW & OC (\%) \\
\hline DtG & 1.00 & & & & & & & & \\
\hline DF & 0.45 & 1.00 & & & & & & & \\
\hline $\mathrm{PH}$ & 0.40 & 0.21 & 1.00 & & & & & & \\
\hline NB & -0.16 & -0.14 & -0.11 & 1.00 & & & & & \\
\hline CapsL & -0.03 & -0.38 & 0.14 & -0.13 & 1.00 & & & & \\
\hline CW & 0.00 & -0.28 & 0.03 & -0.04 & 0.43 & 1.00 & & & \\
\hline Seed length & 0.03 & -0.13 & 0.13 & -0.17 & 0.51 & 0.33 & 1.00 & & \\
\hline Seed width & -0.02 & -0.14 & 0.05 & 0.05 & 0.29 & 0.31 & 0.33 & 1.00 & \\
\hline OC (\%) & 0.02 & -0.09 & 0.38 & 0.19 & 0.06 & -0.01 & 0.00 & 0.09 & 1 \\
\hline
\end{tabular}

with 12 branches plant ${ }^{-1}$. Largest capsule size was observed in 21834 (18.62 mm) followed by 24820, BRC-22 and 22231 with capsule length $18.58 \mathrm{~mm}, 18.55$ and $18.53 \mathrm{~mm}$, respectively. Accession 21559 has largest seed size $(14.27 \mathrm{~mm})$ followed by $21455(14.26 \mathrm{~mm})$ and BRC-13 (14.3 mm). Maximum oil content 58\% was found in genotype 21102 followed by $57 \%$ in 21447 , 5624828 and 54\% in 24835 and 21455. Significant variation was observed for capsule colour as 22 accessions had brown colour capsule followed by skin colour (23), grey (10), dark brown (5), reddish (2) and green (1) (Table 3). Likewise, four types of leaf colour was observed for all genotypes i.e., green $=40$, dark green $=9$, light green $=12$ and purple $=2$ genotypes . Three testa colours were found in population as 42 accessions had grey, 10 accession red and 11 accessions had brown seed coat colour. Majority of the genotypes (84.12\%) in this study were found to have spinney capsules as only 10 accessions were spineless. In our germplasm, oblong type leaf was prevalent which was observed in 45 genotypes followed by ovate type in 18 accessions.

Pearson's correlation among nine quantitative traits including oil content revealed significant association for some morphological traits (Table 4). Highly significant correlation was found between days to germination and days to flowering $\left(0.45^{* *}\right)$. Capsule length was high significantly correlated to seed length $\left(0.51^{* *}\right)$, capsule width $\left(0.43^{* *}\right)$ and seed width $\left(0.29^{*}\right)$. Also, plant height was significantly correlated to days to germination $\left(0.4^{*}\right)$, oil content $\left(0.38^{*}\right)$, days to flowering $\left(0.21^{*}\right)$ and capsule length $\left(0.14^{*}\right)$. Likewise, number of branches plant ${ }^{-1}$ has direct effect on\% oil content $\left(0.19^{*}\right)$. Moreover, there were some inverse association between morphological parameters i.e., days to flowering has significant negative correlation with capsule length $\left(-0.38^{*}\right)$, capsule width $\left(-0.28^{*}\right)$, number of branches $\left(-0.14^{*}\right)$ and seed width $\left(-0.14^{*}\right)$. Similarly, number of branches plant ${ }^{-1}$ were observed to be negatively correlated to seed length $\left(-0.17^{*}\right)$ and capsule length $\left(-0.13^{*}\right)$.

Principal component analysis: Principal component analysis is an important tool to estimate combined effect and contribution of all studied variables in a given population. In the present study PCA was performed for all nine quantitative and five qualitative traits, which elucidated 14 Principal Components (PCs). Only five PCs had Eigen value $>1$, which explained $66.24 \%$ of the total variation in studied population (Table 5). First principal component with Eigen value 3.28 accounted for $23.41 \%$ of the variability in 63 accessions. Main contributors to the $\mathrm{PC}_{1}$ were traits i.e. capsule length, capsule width, seed length and seed width while seed shape and spininess contributed negatively. In $\mathrm{PC}_{2}$ days to germination, days to flowering, plant height and number of branches plant ${ }^{-1}$ delivered $15.17 \%$ variation and capsule colour, capsule length and seed shape had adverse effect on overall component variability. The $\mathrm{PC}_{3}$ with Eigen value 1.5 explained $11.10 \%$ variation that was mainly contributed by number of branches plant ${ }^{-1}$, oil content, leaf colour while seed length, days to germination, capsule colour, days to flowering and testa colour had negative effect on variability. Fourth principal component $\left(\mathrm{PC}_{4}\right)$ with Eigen value represented $8.63 \%$ of total variation in the population, which was attributed due to divergence in phenotypic traits i.e., testa colour, number of branches plant ${ }^{-1}$, seed width, capsule width and spininess. Traits like capsule colour, plant height, oil content and leaf colour attributed negatively to $\mathrm{PC}_{4}$. Principal component 5 characterized $7.94 \%$ of the total 
Sci. Technol. Dev., 34 (3): 147-154, 2015

Table 5: All morphological traits and their contribution to variation in five major principal components

\begin{tabular}{lccrrr}
\hline Variables & $\mathrm{PC}_{1}$ & $\mathrm{PC}_{2}$ & $\mathrm{PC}_{3}$ & $\mathrm{PC}_{4}$ & $\mathrm{PC}_{5}$ \\
\hline E-value & 3.28 & 2.12 & 1.55 & 1.21 & 8.63 \\
Total variation (\%) & 23.41 & 15.17 & 11.10 & 8.16 & 7.94 \\
Cumulative E. value & 3.28 & 5.40 & 6.96 & 58.31 & 9.27 \\
Cumulative variation (\%) & 23.41 & 38.58 & 49.68 & 0.060 & 66.24 \\
Days to germination & -0.004 & 0.741 & -0.215 & 0.069 & -0.037 \\
Days to flowering & -0.358 & 0.731 & -0.172 & -0.192 & 0.312 \\
Plant height & 0.306 & 0.671 & 0.062 & 0.499 & -0.017 \\
No, of branches plant & -1 & -0.121 & 0.698 & 0.192 & 0.118 \\
Capsule length & -0.092 & -0.202 & -0.260 & 0.177 & -0.260 \\
Capsule width & 0.752 & -0.130 & -0.149 & 0.499 & -0.048 \\
Seed length & 0.638 & -0.042 & -0.437 & -0.153 & -0.016 \\
Seed width & 0.555 & -0.032 & -0.031 & -0.252 & 0.575 \\
OC (\%) & 0.542 & 0.223 & 0.561 & -0.124 & 0.564 \\
Capsule color & 0.327 & -0.558 & -0.271 & -0.192 \\
Leaf color & -0.048 & -0.158 & 0.525 & 0.142 & 0.688 \\
Spininess & 0.267 & -0.003 & -0.076 & -0.002 & 0.474 \\
Testa color & -0.808 & 0.025 & -0.139 & -0.131 & 0.062 \\
Seed shape & -0.263 & -0.358 & & & \\
\hline
\end{tabular}

phenotypic variation among all accessions as plant height, oil content, capsule and testa colour were main contributors towards variability. Capsule width, leaf colour and plant height had minor negative effect on $\mathrm{PC}_{5}$ variation.

Scatter plot depicted wide distribution of all 63 accessions across axis largely on the basis of phenotypic traits (Fig. 1). Moreover, at least four major strata or sub-population were illustrated in studied germplasm akin to their morphological attributes (Fig. 2). Sub-population I have tallest and early flowering genotypes which performed above average for oil content and yield related traits. Sub-population II comprised of spiny accessions with smallest capsules and lowest oil content. Sub population III and IV comprised of average performing genotypes and short statured late flowering accessions with lowest oil content. This produced slight pattern of certain accessions classification having background from common district/region to settle to gather in a specific group or sub-population i.e., accessions and varieties of Bahawalpur and adjoining districts clustered in sub-population I (Fig. 2). Similarly sub population II comprised of genotypes from five adjoining districts i.e., Bahawalpur, Lodhran, Multan, Muzaffargarh and D.G Khan. Third sub-population was inconsistent with geographical proximity as accessions from Sindh (Ghotki) and Balochistan (Loralai) agronomically performed identical to accessions of South Punjab for various qualitative and quantitative traits. Again, the fourth group was attributed to 4 adjacent districts i.e., Sahiwal, Khanewal, Multan and Muzaffargarh. However, an outright configuration of accessions exclusively collating with the geographical origin of the genotypes was not observed in PCA as accessions of more than 2 districts shared same position in a scatter plot. Contribution of morphological traits for $\mathrm{PC}_{1}$ and $\mathrm{PC}_{2}$ and PCA based distribution of accessions in first two PCs has been shown in scattered diagrams (Fig. 1 and 2).

Cluster analysis: Inter-relatedness among germplasm was studied using Euclidean distances for both quantitative and qualitative traits. The dissimilarity coefficient matrix depicted minimum Euclidean distance 1.65 between accessions BRC-26 and 21103 followed by 1.86 between 21103 and 21110 and 1.91 between 21106 and BRC-26. However, accessions pairs 24816 and 24821, 24821 and 24829, 21559 and 24821 made most diverse with highest Euclidean distances i.e. 11.45, 10.49 and 9.88, respectively. On average, inter-accession Euclidean distance of 4.85 was recorded, which denote ample divergence in population structure of Pakistani castor germplasm. Dendrogram was generated on the basis of similarity index, classifying all 63 genotypes into six major clusters at 6.5 dissimilarity coefficient (Fig. 3). Group I included 7 accessions having shortest height (114.27), highest number of branches plant ${ }^{-1}$ (8) and smallest seeds $(7.07 \mathrm{~mm})$. Group II and III each comprised of ten low oil content (44.3\%) accessions with spiny and smallest capsules (163 mm) and oblong type leaves. Twelve average performing accessions clustered in group IV as they performed well below maximum for most of the agronomic traits as well as oil content. The fifth group was largest having 16 tallest and earliest to flower accessions. Besides, these genotypes had largest spiny capsules $(13.2 \mathrm{~mm})$ with healthy seeds $(11.2 \mathrm{~mm})$. Group VI has seven accessions with mediocre agronomic performance and above average oil content (46.4\%). Accession 24821 stood alone in the cluster due to unique attributes i.e., least number of branches plant $^{-1}$ (6), largest capsules $(17.67 \mathrm{~mm})$, maximum seed length $(9.90 \mathrm{~mm})$, seed width $(7.26 \mathrm{~mm})$ and highest oil content average (59\%). 


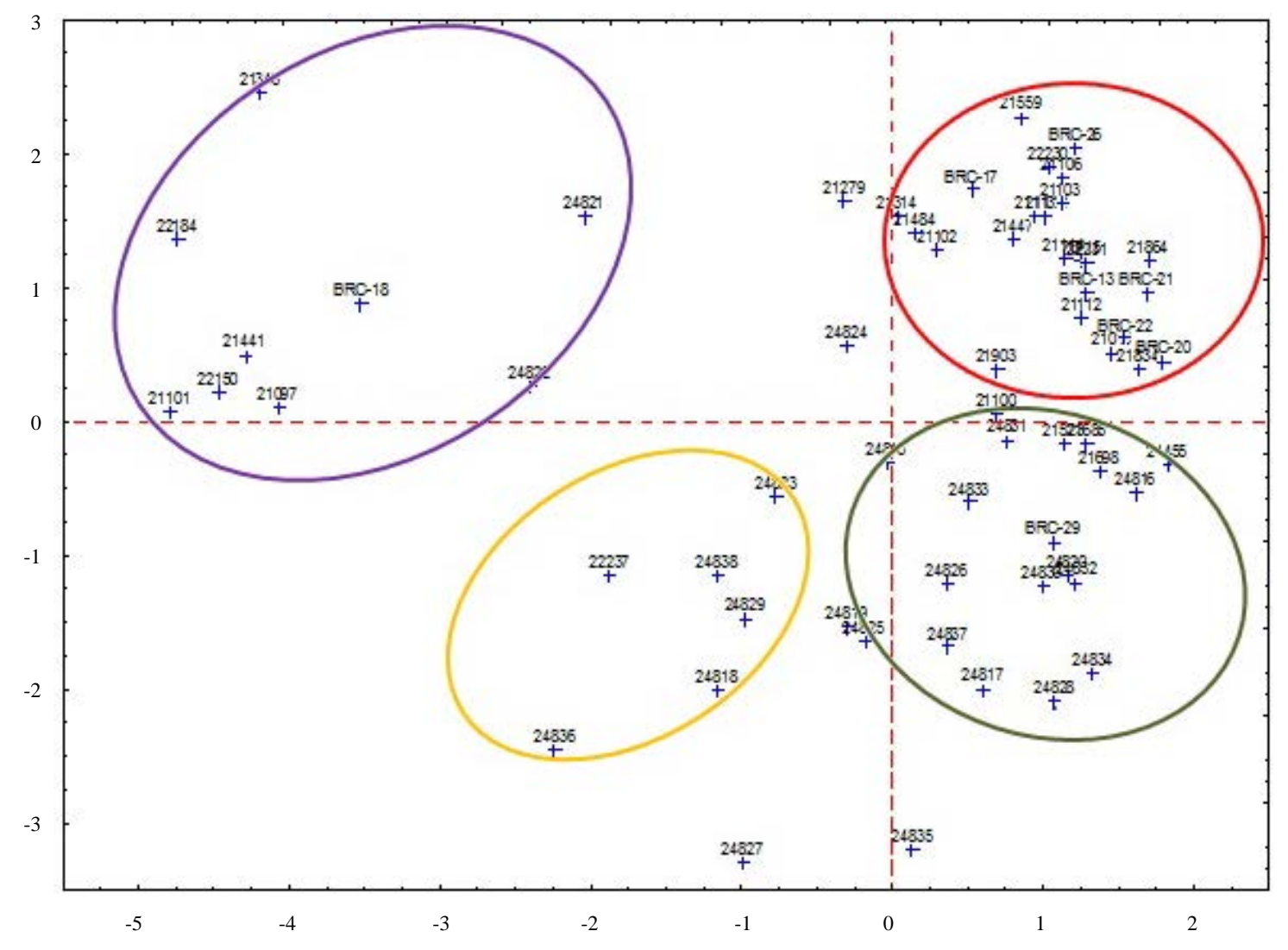

Fig. 1: Agro-morphological characterization based PCA scatter diagram showing all 63 genotypes dispersed in 4 encircled distinct sub-populations i.e., I = red, II = green, III = blue and IV = yellow

\section{DISCUSSION}

Studying phenotypic divergence is initial step to document extent of overall genetic diversity present in the plant population. In order to determine requirements of conservation status of particular species, spatial and temporal aspects are important determinants to be considered, while developing preservation strategy (Loveless and Hamrick, 1984). Recently, some studies have been conducted to report genetic variation in castor bean (Ricinus communis L.) through phenotypic characterization (Sarwar et al., 2010; Goodarzi et al., 2012; Ahmed et al., 2012). In present study oil content and other important agronomic descriptors revealed a moderate level of genetic divergence in Pakistani castor germplasm. Likewise population structure was observed in local genetic stocks of Punjab region through principal component and cluster analysis. We observed high level of variability for traits i.e. number of branches plant ${ }^{-1}$, plant height, days to germination, days to flowering and oil content, seed length and capsule width. Comparable results were reported by Goodarzi et al. (2012) while studying morphological characterization based genetic variation in castor bean population of Iranian origin. Ahmed et al. (2012) also observed morphological variation in castor mutant lines for days to maturity, plant height, number of spikes plant ${ }^{-1}$, capsule yield plant ${ }^{-1}$, 100 -seed weight and seed yield plant ${ }^{-1}$. These characters offer higher variability and also suggested to be governed by additive gene effect (Sarwar and Haq, 2005, 2006) hence could be utilized as parameters in selection criteria for superior genotypes among population.

We observed association among various agronomic traits which was supported by findings of Ahmed et al. (2012), which noted strong positive correlation between days to maturity and plant height, main spike and number of capsules, capsule yield and seed yield. Sarwar et al. (2010) recorded similar results from Pearson's correlation of different characters and detected strong positive association seed yield with height 


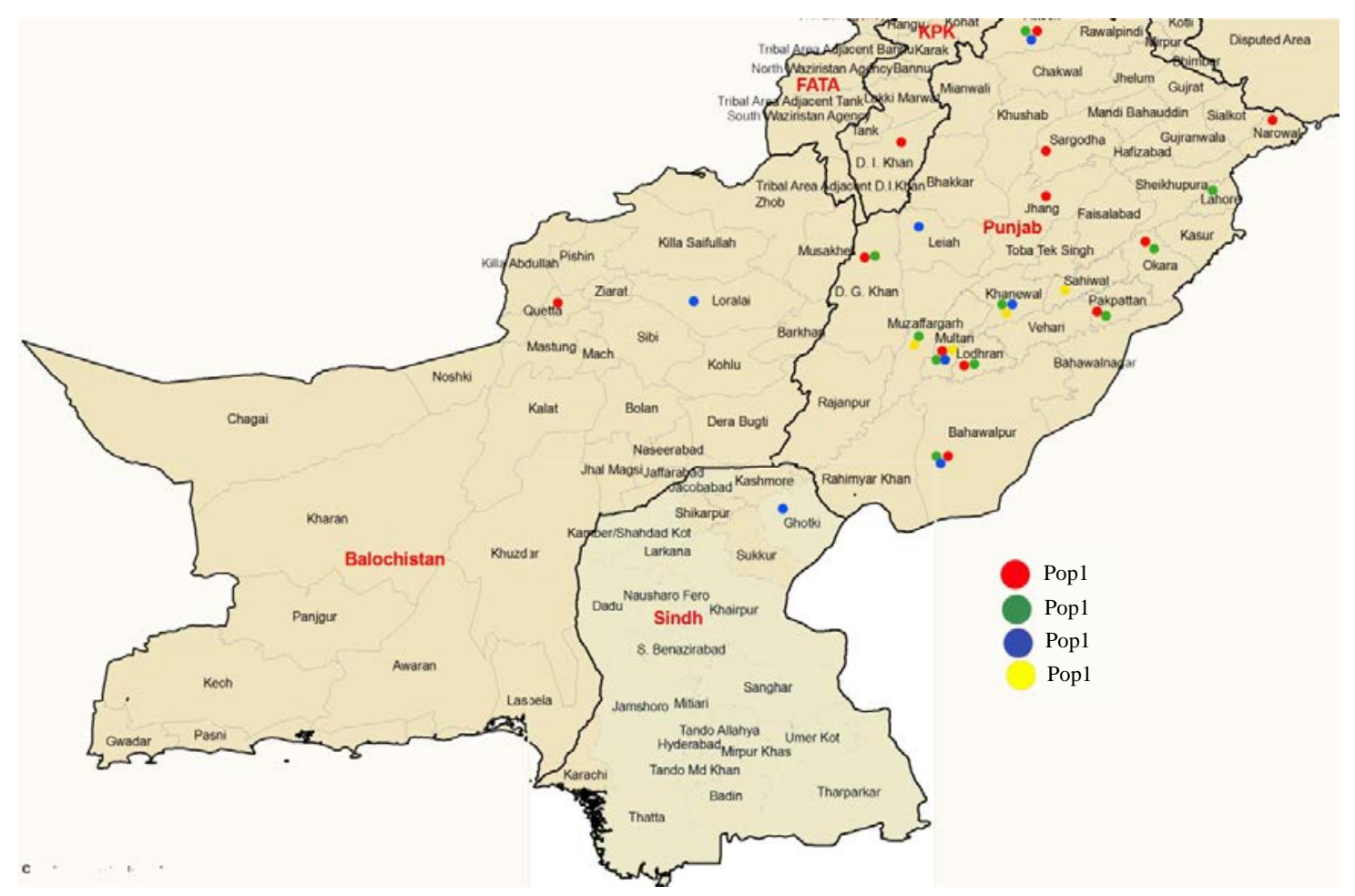

Fig. 2: Geographical distribution of 4 castor beans subpopulations across 3 provinces of Pakistan

and main shoot length and negatively associated with capsules number per spike and 100-seed weight, whereas spikes number per plant were found to be negatively associated with capsules number per spike. Results of previous studies in castor bean by Lima et al. (1998) and Reddy et al. (1999) were in also in complete agreement with our findings.

Multivariate analysis stratified studied germplasm into groups and sub-populations mainly on the basis of agro-morphological characteristics while significant geographical pattern was absent. This lack of a noticeable geographical pattern for castor bean diversity was also documented by Allan et al. (2008), while studying AFLPs and SSRs based genetic divergence in global germplasm. However, though to a lesser degree, minor configuration for area specificity was evident from PCA analysis as 4 distinct classes were observed in the population. These sub-populations originated from common habitat comprising of neighbouring districts with identical agro-climatic conditions. Partitioning of genetic variability is essential for conservational strategies due to strong impact of subdivisions sampling on measurement of overall genetic diversity in a given space (Cavalli-Sforza and Feldman, 1990). The phenotypic variation in a relatively small region signifies availability of genetic diversity in south Punjab. Moreover, accessions from remote regions like Attock, Ghotki (Sindh), Loralai and Quetta (Balochistan) exhibited identical agro-morphological characters, negating any direct relation between genetic divergence and their spatial distribution across Pakistan. This can be attributed to probable migration of germplasm which in turn can impose spatial structure which also depends on the distance between subdivisions generating correlation between neighbouring populations (Rao and Hodgkin, 2002). It can be inferred that though promising extent of castor beans genetic diversity is available in south Punjab areas, where population structure confirms phenotypic divergence but overall variation appears to be limited across Punjab, Sindh and Balochistan regions. Available Geographic distribution is strongly dependent on ecogeographic factors, such as latitude, altitude, temperature and humidity etc., while similarity in these factors leads to a narrow genetic diversity in the available germplasm (Rao and Hodgkin, 2002). This lower level of genetic variability can also be attributed to over domestication, long term cultivation of selective genotypes, gene flow and smaller population size (Allan et al., 2008; Goodarzi et al., 2012). Besides, oil content offered significant variability as well as enhanced quantity ( $55 \%)$ in Pakistani castor bean population, whereas 


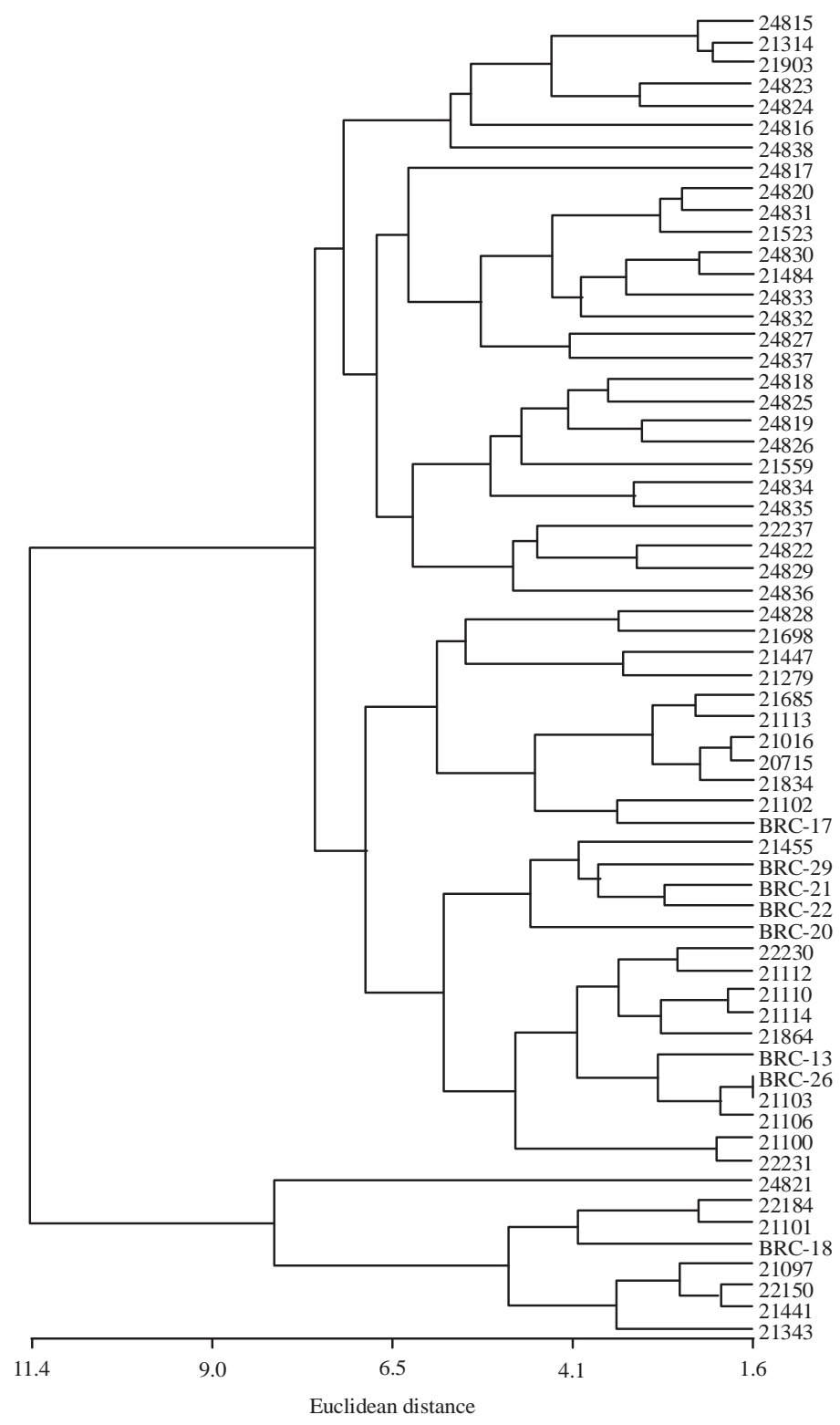

Fig. 3: Euclidean distance based cluster analysis for agro-morphological variation distributing all 63 genotypes in 6 major groups

previous studies have reported meagre $42-45 \%$ oil content in castor bean (Vanaja et al., 2008; Goodarzi et al., 2012). Accessions 21102, 21447, 21455, 24828 and 24835 with oil content more than 50\% could be utilized in selection as parental lines while breeding for improved oil content.

\section{REFERENCES}

Ahmed, H.M., G. Sarwar and M. Ahsan ul Haq, 2012. Genetic variability and interdependence of morphological traits in castorbean (Ricinus communis L) mutants. Songklanakarin J. Sci. Technol., 34: 279-286.
Allan, G., A. Williams, P.D. Rabinowicz, A.P. Chan, J. Ravel and P. Keim, 2008. Worldwide genotyping of castor bean germplasm (Ricinus communis L.) using AFLPs and SSRs. Genet. Resour. Crop Evol., 55: 365-378.

Anjani, K., 2012. Castor genetic resources: A primary gene pool for exploitation. Ind. Crops Prod., 35: 1-14.

Camussi, A., E. Ottaviano, T. Calinski and Z. Kaczmarek, 1985. Genetic distances based on quantitative traits. Genetics, 111: 945-962. 
Cavalli-Sforza, L.L. and M.W. Feldman, 1990. Spatial subdivision of populations and estimates of genetic variation. Theoret. Popul. Biol., 37: 3-25.

Falasca, S.L., A.C. Ulberich and E. Ulberich, 2012. Developing an agro-climatic zoning model to determine potential production areas for castor bean (Ricinus communis L.). Ind. Crops Prod., 40: 185-191.

Goodarzi, F., R. Darvishzadeh, A. Hassani and A. Hassanzaeh, 2012. Study on genetic variation in Iranian castor bean (Ricinus communis L.) accessions using multivariate statistical techniques. J. Med. Plants Res., 6: 1160-1167.

Hegde, D.M., M. Sujatha and N.B. Singh, 2003. Castor in India. Directorate of Oilseeds Research, Indian Council of Agriculture Research, Hyderabad, India, Pages: 117.

Lima, E.F., J. Santos and W. Dos, 1998. Genotypic, phenotypic and environmental correlations among agronomic characteristics of castorbean (Ricinus communis L.). Revista Oleaginosas Fibrosas, 2: 147-150.

Loveless, M.D. and J.L. Hamrick, 1984. Ecological determinants of genetic structure in plant populations. Annu. Rev. Ecol. Syst., 15: 65-95.

Nooryazdan, H., H. Serieys, R. Bacilieri, J. David and A. Berville, 2010. Structure of wild annual sunflower (Helianthus annuus L.) accessions based on agromorphological traits. Genet. Resour. Crop Evol., 57: 27-39.

Ogunniyi, D.S., 2006. Castor oil: A vital industrial raw material. Bioresour. Technol., 97: 1086-1091.

Peeters, J.P. and J.A. Martinelli, 1989. Hierarchical cluster analysis as a tool to manage variation in germplasm collections. Theor. Applied Genet., 78: 42-48.
Rao, V.R. and T. Hodgkin, 2002. Genetic diversity and conservation and utilization of plant genetic resources. Plant Cell Tissue Org. Cult., 68: 1-19.

Reddy, P.R., M. Vanaja, G.R. Sankar, C.H. Rao, S. Venkateswarlu and J.D. Eastin, 1999. Yield components in castor germplasm under irrigated and rainfed conditions. J. Maharashtra Agric. Univ., 24: 36-41.

Sarwar, G. and M.A. Haq, 2005. Radiation-induced variability for the improvement of yield and yield components in sesame (Sesamum indicum L.). Sesame Safflower Newslett., 20: 42-47.

Sarwar, G. and M.A. Haq, 2006. Evaluation of sesame germplasm for genetic parameters and disease resistance. J. Agric. Res., 44: 89-95.

Sarwar, G., H.M. Ahmed and J. Hussain, 2010. Evaluation of castorbean (Ricinus communis L.) mutants for genetic parameters and cluster analysis. J. Agric. Res., 48: 289-302.

Smith, S.E., A. Al-Doss and M. Warburton, 1991. Morphological and agronomic variation in North African and Arabian alfalfas. Crop Sci., 31: 1159-1163.

Sujatha, M., T.P. Reddy and M.J. Mahas, 2008. Role of biotechnological interventions in the improvement of castor (Ricinus communis L.) and Jatropha curcas L. Biotechnol. Adv., 26: 424-443.

Vanaja, M., M. Jyothi, P. Ratanakumar, P. Vagheera and P.R. Reddy et al., 2008. Growth and yield responses of castor bean (Ricinus communis L.) to two enhanced $\mathrm{CO}_{2}$ levels. Plant Soil Environ., 54: 38-46.

Weiss, E.A., 2000. Castor. In: Oilseed Crops, Weiss, E.A. (Ed.). 2nd Edn., Blackwell Scientific Ltd., Oxford, UK., ISBN-13: 9780632052592, pp: 13-52. 